\title{
Sciendo
}

DOI 10.2478/afepuc-2019-0006

(C) Acta Facultatis Educationis Physicae Universitatis Comenianae 2019, 59(1): 69-78

\section{ALGERIAN SPORT HIGH SCHOOL AS COMPREHENSIVE APPROACH FOR IMPROVING PUBLIC EDUCATION SYSTEM}

\author{
Reguig Madani', Mohammed Zerf ${ }^{1}$, SBA Bouabdellah ${ }^{2}$ \\ ${ }^{1}$ Faculty of Sport and Physical Education University of Mostaganem, Algeria \\ ${ }^{2}$ Faculty of Sport and Physical Education University Hassiba Ben Bouali of Chlef, Algeria
}

\begin{abstract}
Summary. In 2001 Algerian Governmental created Sport High School (HSA). Its main mission is education, training and development of young talents by providing all the conditions to serve their healthy sports path. Firstly, by intensifying their daily sports as school-based health education program designed to improve their physical status relates to their healthy lifestyle. Disclosed by evaluation tool design to detect their physical abilities as well as their longitudinal followings. Used in present as evaluation scale to inspect imprudence related to the objectives of Algerian public schools (HPA). For proposing this comparative study test 1000 High School student, 800 boys and 200 girls for academic years 2017 2018. The evaluation focused on measuring anthropometric parameters - age, weight, height and BMI as well as physical qualities - speed $(30 \mathrm{~m})$, the explosive force vertical (VJ), explosive force of the arms (medicine ball throw $3 \mathrm{~kg}(\mathrm{MB})$, flexibility trunk (FT)), endurance abdominal muscles (maximum of $<4$ sit-ups $>$ in one minute (EAM) and aerobic endurance (20m shuttle test (VO2max)). Controlled by rating scales produced by Iaiche Rezoug. Based on the scale provided by this latter, our results proclaims the generalization of perspectives implemented in Algerian Sport High School as school-based physical health education program designed to reduce the consequences of overweight on health-related to physical performance. Estimated by rating scales produced by Iaiche Rezoug, which could serve as a model database refining the impact of the two Algerian educational systems, as an approach suggesting a clear direction for the development of adequate programs for the larger populations of Algerian scholars.
\end{abstract}

Keyword: Sport High School, Public High School, policies, physical health and well-being. 


\section{Introduction}

In recent decades the role of recess during the school day has been called into question. Reviewed by (Bohn-Gettler \& Pellegrini 2014) to ensure the best practices are being utilized, school policies should be based on scientific investigations. Proclaims by Ling Qian, Lok-Wa Yuen, Yonghua Feng, Ian Newman, Duane Shell, Weijing (2018) via a school-based comprehensive health education program that would effectively increase children's physical activity level. Support the encouragement of physical activity facilities and opportunities, under the school environment that encourages teenagers to be active around after time school. Below its administration, that allows $60+$ minutes per school day for physical activities, and assigning quantities of homework that restrict play outside of school hours (Feng, Wei, Lin, Maddison, Ni Mhurchu, Jiang et al. 2017). However, this practice in Algerian educational system is in conformity with Algerian High School Sport created in 2001; its main mission is education, training and development of young talents (Aiche Rezoug 2007). In the opposite of public school where the time of physical lessen is limited to $2 \mathrm{~h} /$ weeks in middle or high school (Zerf 2016). From this perspective, our outcome in this study reveals the result of these contradictions two Algerian governmental educational approaches that one of them support sport-schoolbased intervention programs. As policies classrooms for health education by facilitating exercise daily practice as beneficial health related to fitness and well-being (Wang, Cai, Wu, Wilson, Weston, Fawole et al. 2015). Where the other reduced time of physical activity improves the academic results. Dined by Algerian studies as sedentary time physical inactivity contribute substantially to the global burden of disease. Affirmed by Zerf (2016) as based school ideal environment for delivering obesity interventions to children because students spend most of their waking time at school (at least eight hours per day) (Mohammed 2017). Assumed in present by evaluation scale developed by Iaiche Rezoug (2007) in its aim is to refine the detection of the physical aptitudes of young sports students. In addition to present study, that their aims are to revel imprudence interconnected to the objectives of Algerian public schools. Indicated by similarities through the implementation of more time of physical lessons or additional physical program look at increase of relationship physical health indicators and reduction of to obesity and other syndromes. Report Physical Fitness and Health Surveillance Survey(NPFHS) as comprehensive school-based interventions may assist in tackling the rising prevalence of child and adolescent obesity scholars. 


\section{Method}

\section{Study population and design}

Our aim in this study is to reveal the impact of two Algerian governmental educational approaches: High School Sport (HAS) created by Algerian Governmental, versus Algerian public schools (HPA) conducted in "PE Institute" University of Mostaganem for academic years 2017-2018. The research samples were selected by intentional manner included 800 male secondary high school students and 200 girls, their age are around 16 years. All participants were healthy with good habits not taking any medication on a regular basis. Their results were compared by in one hand by a scale developed by Iaiche Rezoug (2007) as well as its study results. All contributors were informed about procedures and all participants provided their written consent. The study protocol was accepted by the Institute of PE. The study was conducted based on the field tests physical qualities and BMI, third semester, 19 May 2018 on the student festival in the Mostaganem sports complex:

- Speed $(30 \mathrm{~m})$ : The test involves running a single maximum sprint over 30 meters, with the time recorded. Below are average for the $30 \mathrm{~m}$ SPRINT (Davis, Phillips, J. Roscoe \& D. Roscoe 2000) for age 14 to 18 years.

Table 1

Norms 30 m sprint for age 14 to 18 years (Davis, Phillips, J. Roscoe \& D. Roscoe 2000)

\begin{tabular}{|c|c|c|c|c|c|}
\hline Gender & Excellent & Above Average & Average & Below Average & Poor \\
\hline Male & $<4$ & $4.0-4.2$ & $4.3-4.4$ & $4.5-4.6$ & $>4.6$ \\
\hline Female & $<4.5$ & $4.5-4.6$ & $4.7-4.8$ & $4.9-5.0$ & $>5.0$ \\
\hline
\end{tabular}

- Explosive force (VJ)): also known as the vertical jump test (Davis, Phillips, J. Roscoe \& D. Roscoe 2000) for ages 14 to 18 years.

Table 2

Norms of vertical jump test for age 14 to 18 years (Davis, Phillips, J. Roscoe \& D. Roscoe 2000)

\begin{tabular}{|c|l|l|c|l|c|}
\hline Gender & Excellent & Above Average & Average & Below Average & Poor \\
\hline Male & $>65 \mathrm{~cm}$ & $50-65 \mathrm{~cm}$ & $40-49 \mathrm{~cm}$ & $30-39 \mathrm{~cm}$ & $<30 \mathrm{~cm}$ \\
\hline Female & $>58 \mathrm{~cm}$ & $47-58 \mathrm{~cm}$ & $36-46 \mathrm{~cm}$ & $26-35 \mathrm{~cm}$ & $<26 \mathrm{~cm}$ \\
\hline
\end{tabular}

- Explosive force of the arms (medicine ball throw $3 \mathrm{~kg}(\mathrm{MB})$ ): This test measures upper body (arm) strength and explosive power, the distance from the starting position to where 
the ball lands are recorded. Medicine ball $-3 \mathrm{~kg}$ request weight up to $65 \mathrm{~kg}$ body weight. For ages 14 to 18 years (Howley \& Thomas 2016).

Table 3

Norms of the explosive force of the arms for age 14 to 18 years (Davis, Phillips, J. Roscoe \& D. Roscoe 2000)

\begin{tabular}{|c|c|c|c|c|c|}
\hline Gender & Excellent & Above Average & Average & Below Average & Poor \\
\hline Male & $>6,5 \mathrm{~m}$ & $5,0-6,5 \mathrm{~m}$ & $4,0-4,9 \mathrm{~m}$ & $3,0-3,9 \mathrm{~m}$ & $<3,0 \mathrm{~m}$ \\
\hline Female & $>5,8 \mathrm{~m}$ & $4,7-5,8 \mathrm{~m}$ & $3,6-4,6 \mathrm{~m}$ & $2,6-3,5 \mathrm{~m}$ & $<2,6 \mathrm{~m}$ \\
\hline
\end{tabular}

- Flexibility (bending of the trunk (FK)): The objective of this test is to monitor the development of the athlete's lower back and hamstring flexibility. The assistant records the distance reached by the athlete's fingertips $(\mathrm{cm})$ and following table is for 16 to 19 year-olds (Davis et al. 2000, p. 126).

\section{Table 4}

Norms of trunk flexibility for age 14 to 18 years (Davis, Phillips, J. Roscoe \& D. Roscoe 2000)

\begin{tabular}{|c|c|c|c|c|c|}
\hline Gender & Excellent & Above Average & Average & Below Average & Poor \\
\hline Male & $>14$ & $14.0-11.0$ & $10.9-7.0$ & $6.9-4.0$ & $<4$ \\
\hline Female & $>15$ & $15.0-12.0$ & $11.9-7.0$ & $6.9-4.0$ & $<4$ \\
\hline
\end{tabular}

- Endurance abdominal muscles (maximum of $<4$ sit-ups $>>$ in one minute (EAM)). This test requires the athlete to complete as many curl-ups as possible at a rate of $20 /$ minute. The athlete is to perform as many curls as $\mathrm{p}$ he assistant is to count and record the total number of curls which is then used to assess the athlete's performance possible until they are unable to keep in time with the metronome. The following normative data is available for this test (Hyde 2002).

Table 5

Present the norms of the endurance of abdominal muscles for age 14 to 18 years (Davis, Phillips, J. Roscoe \& D. Roscoe 2000)

\begin{tabular}{|c|c|c|c|c|c|}
\hline Gender & Excellent & Above Average & Average & Below Average & Poor \\
\hline Male & $>55$ & $54.0-49.0$ & $48-47.0$ & $46.9-40.0$ & $<40$ \\
\hline Female & $>50$ & $49.0-45.0$ & $44-40.0$ & $39-31$ & $<30$ \\
\hline
\end{tabular}

- Aerobic endurance (through the 20 m shuttle test $\left(\mathrm{VO}_{2} \mathrm{max}\right)$ ): designed to determine the maximal aerobic power of schoolchildren, healthy adults attending fitness class and athletes performing in sports with frequent stops and starts (e.g. basketball, fencing and so on). Subjects run back and forth on a $20 \mathrm{~m}$ course and must touch the $20 \mathrm{~m}$ line; at the same time, a sound signal is emitted from a pre-recorded tape. Frequency of the sound 
signals is increased by $0.5 \mathrm{~km} \mathrm{~h}-1$ each minute from a starting speed of $8.5 \mathrm{~km} \mathrm{~h}-1$. When the subject can no longer follow the pace, the last stage number announced is used to predict maximal oxygen uptake $\left(\mathrm{VO}_{2} \mathrm{max}\right)(\mathrm{Y}, \mathrm{ml} \mathrm{kg}-1 \mathrm{~min}-1)$ from the speed $\left(\mathrm{X}, \mathrm{km} \cdot \mathrm{h}^{-1}\right)$ corresponding to that stage (speed $=8+0.5$ stage no.) and age (A, year): $\mathrm{Y}=31.025+$ $3.238 \mathrm{X}-3.248 \mathrm{~A}+0.1536 \mathrm{AX}, \mathrm{r}=0.71$ with 188 boys and girls aged 8-19 years (Léger, Mercier, Gadoury, Lambert 1988)

- Anthropometric parameters: we calculate age by years, weight $(\mathrm{kg})$, height $(\mathrm{cm})$ and body mass index (BMI) by formula BMI = weight/square meter size (Mohammed 2017).

\section{Statistical analysis}

The study was not a research project, but an evaluation comparative of educational practices in our educational settings. Descriptive analysis of students based on means and percentage drives from physical tests, according to (Iaiche Rezoug 2007) scale results and battery tests. Present in this study as fugues 1 , and 2.

\section{Result}

The results of figure 1 showed that Algerian Governmental High School Sports students obtained higher scores than students Algerian public schools. Records in all parameters studies. Support by Algerian studies that inactive course and lack of sport are predictors of health problems that may lead to severe consequences (Zerf 2016). Demonstrated by reviews studies through a comprehensive sport based-school health education, that includes effective instruction for developing knowledge, skills, motivation, and changes to the school's physical and social environment (Ling Qian, Lok-Wa Yuen, Yonghua Feng, Ian Newman, Duane Shell, Weijing 2018). Deduce by this study through school-based interventions effective for reducing BMI in teenagers, with a change of BMI ranging from $-0.04 \mathrm{~kg} / \mathrm{m} 2$ to $-3.27 \mathrm{~kg} / \mathrm{m} 2$, according to Wang, Cai, Wu, Wilson, Weston, Fawole et al. 2015). Top scored in actual study in figure 2 following standardizing data obtainable by (Iaiche Rezoug, 2007). See figure 1. 


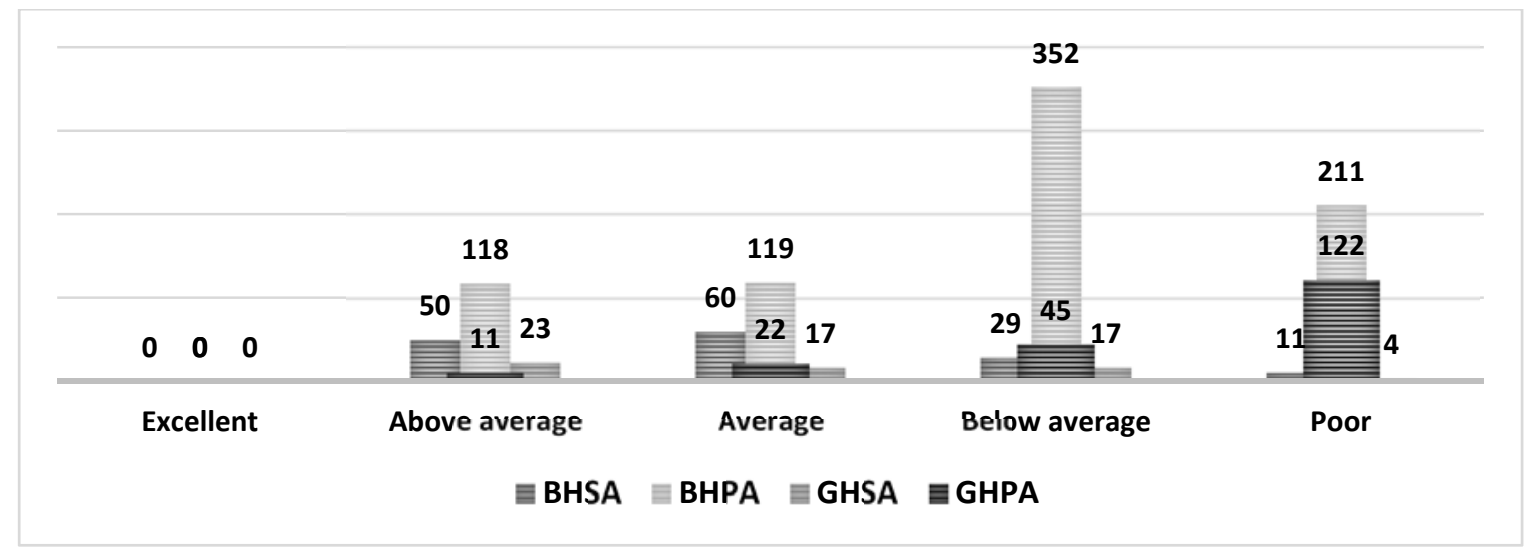

Figure 1

Characteristics of the two samples following normative data obtainable by Iaiche Rezoug (2007)

Recommend in Algerian studies via the subject of significant time physical education course as a treatment to inactive course elements. Recognized as a significant risk factor for multiple causes, like increases of stroke, cardiovascular, elevated blood pressure, low HDL ("good") cholesterol and diabetes (Zerf 2016). Conclude in the case of this study via the principle that any work domain demands some strength and physical capacity. In respect to the relationship between fitness practice and educational global programs (Cook 2016). Report as just cause motion in figure 2 .

Figure 2

Percentage of physical of the two samples following normative data obtainable by Iaiche Rezoug (2007)

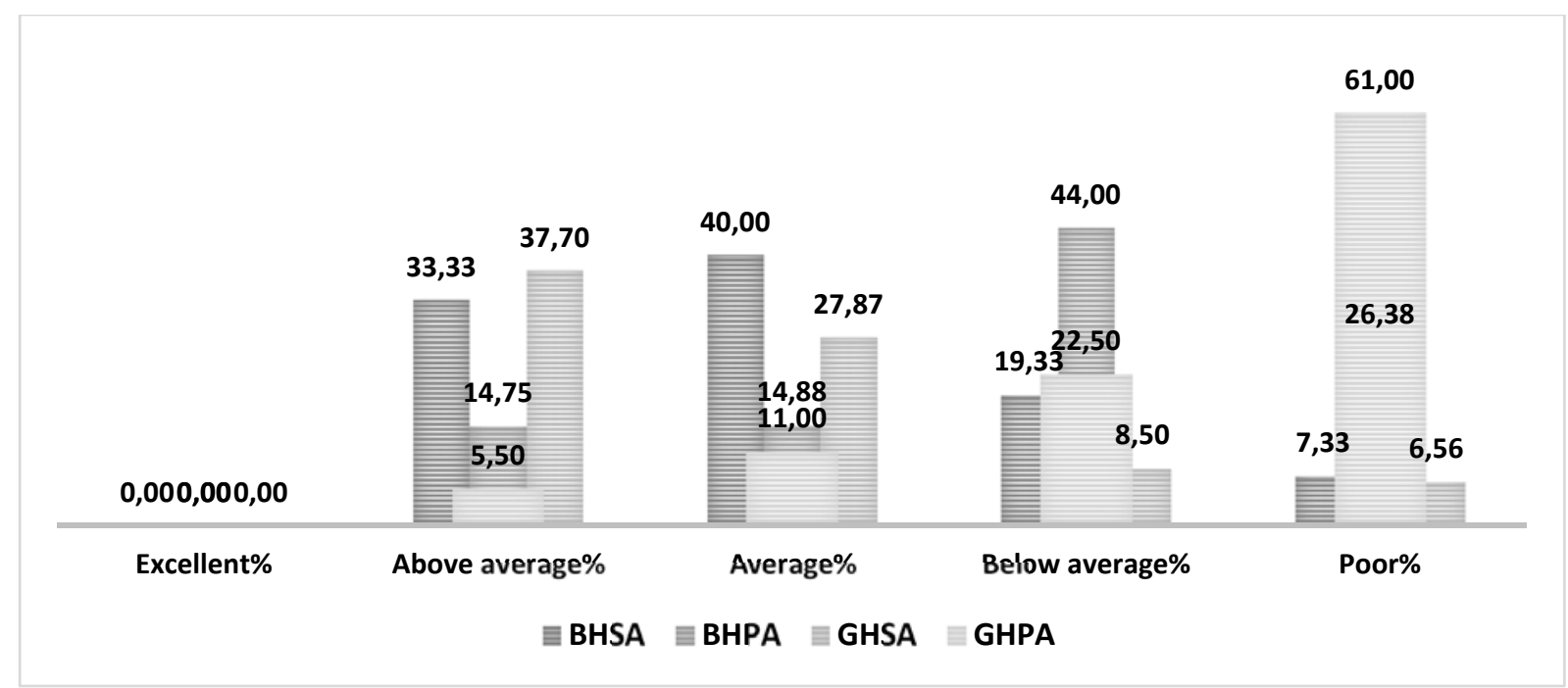

In benefits of Algerian Governmental High School Sports students (BHSA and GHSA) as efficacy school-based comprehensive physical and health education program in all variables 
studies. The opposite of students Algerian public schools that the mode of school is associated with exercise intolerance and many adverse health consequences related to weight- obesity, overweight, upper BMI, adiposity, and an increase of fat, dined in Algerian studies (Mohammed 2017). Confirmed by standard battery test proposed by Iaiche Rezoug (2007). Stated by (Mohammed 2017) as missing Health Fitness Control Practices in Algerian Secondary School. In the benefits of extracurricular physicals relate to fitness, as both missing health-fitness control and practices in PE Algerian public school curricular Secondary School.

\section{Discussion}

Our results confirmed that school-based interventions Algerian public schools are associated with many adverse health consequences, including exercise intolerance, upper BMI, and negative self-body image and physical performance (Ebbeling, Pawlak, Ludwig 2002). Confirmed via this study Algerian Governmental High School Sports students (BHSA and GHSA) as efficacy school-based comprehensive physical and health education program in all criteria studies. Admitted by Yang (2014) that School Sports Prescription" seemed to be an effective physical activity intervention widely applied in treatment studies, which generally organized more minutes physical activities guided by specific prospectuses after class in school days, focused on moderate intensity aerobic exercise complementary with strength and fitness training. Shown by Algerian studies that specific enhancements to PE classes can effectively increase levels of physical activity and improve physical fitness among children and adolescents. Extra benefits may include improved flexibility, muscular endurance, and exercise-related knowledge and motivation (Mohammed 2017). Report by (Bohn-Gettler \& Pellegrini 2014) via the activity levels of PE classes can be enhanced by adjusting curricula, teaching practices, or policies. The case of Algerian Governmental High School-based Sports students (BHSA and GHSA) that activity levels of PE classes by improving the Algerian high school academic curricula, teaching practices, or policies. Admitted by our government as specific strategies by increasing the time or level of physical activity in those specific classes by altering the rules of games or using teaching techniques to maintain all students engaged and active; adding PE classes to the school day or week; or extending the length of PE class time (Iaiche Rezoug 2007). Show in the present as healthy implements that must be globally applicable to public elementary, middle, and high school students to aid them achieve the recommended 60 minutes of activity every day (Feng, Wei, Lin, Maddison, Ni Mhurchu, Jiang 
et al. 2017). Purposed in similarities as school-based physical programs that increase daily students' physical activity levels by encouraging them to improve their fitness levels. As practice to maintain a healthy weight and potentially improve their health outcomes over time. Evidence confirmed by reviews that these interventions are associated with beneficial effects on BMI and obesity prevention (Mohammed 2018). Our results caution against school-based time active versus inactive on levels of health relate to fitness. Below the implements difference between sport high school and public Algerian secondary academic system. Admit in five motor abilities namely strength, speed, endurance, flexibility and coordinative abilities, agreeing to present study. Reported in the benefit of student scholar in sport Algerian high school in competences with public students' school. From that, our outcome in this study reveals the contradictions between those two Algerian governmental academic approaches that one of them supports sport-school-based intervention programs. As policies classrooms for health education by facilitating exercise ordinary practice as beneficial health related to fitness and well-being (Wang, Cai, Wu, Wilson, Weston, Fawole et al. 2015). Claims by Algerian studies the case of public schools as sedentary time physical inactivity increases global burdens of disease. Affirmed by Zerf (2016) as based school ideal environment for increasing obesity. Since students spend most of their waking time at school (at least eight hours per day) (Mohammed 2017). Expected in present by the scale developed by (Iaiche Rezoug 2007) to jug the physical aptitudes of adolescent students. Present via this study as missing healthy fitness control practices in Algerian Secondary School to revel rashness interconnected to the objectives of Algerian public schools. Indicated by similarities through the effecting of more time of physical lessons or supplemental physical program Look at increasing of relationship physical health indicators and reduction of obesity and other syndromes. Report Physical Fitness and Health Surveillance Survey (NPFHS). As comprehensive school-based interventions may help in tackling the rising frequent incident of children and adolescent obesity scholars (Qian, Yuen, Feng, Newman, Shell, Du 2018)

\section{Conclusions}

Longitudinal data have shown that for each weekday that normal weight adolescents participated in physical education, the odds of becoming an overweight adult decreased by 5 percent. Estimated via this study standards measure test and time physical practice. Which support a comprehensive school physical activity program and emphasize daily and minimum 
time necessities, curriculum and assessment standards, and certified teachers with appropriate class sizes and equipment. Concludes by review studies to be up to an hour of daily physical activity programs. Which can be added to a school curriculum by taking time from other subjects without hurting students' academic achievement in those subjects. Reported in the present study at benefits of Algerian students' academic in sport Algerian high school in compares with Algerian public students' school. Claims by present as physical healthy implements, that must be globally applied to public elementary, middle, and high school students. To aid them for achieving the recommended 60 minutes of activity every day. Show through this study as missing policies promoting standards for instructors' qualifications, fitness testing, or performance in Algerian public schools. Where majors studies in this topic admitted that it does not enhance the students' grades either in these subjects or in their physical fitness.

\section{References}

1. BOHN-GETTLER, C. \& A. PELLEGRINI, 2014. Recess in Primary School: The Disjuncture Between Educational Policy and Scientific Research. Springer, New York, NY.

2. CHERYL L. HYDE, 2002. Fitness instructor training guide. Dubuque: Iowa Kendall Hunt.

3. COOK, M., 2016. Personnel Selection: Adding Value Through People - A Changing Picture. US: Wiley.com.

4. EBBELING, C. B., D. B. PAWLAK \& D. S. LUDWIG, 2002. Childhood obesity: publichealth crisis, common sense cure. Lancet. 360(9331), 473-82. Retrieved from pmid:12241736.

5. FENG, WEI, LIN, MADDISON, NI MHURCHU, JIANG et al., 2017. Systematic review and meta-analysis of school-based obesity interventions in mainland China. PLoS ONE. 12(9), e0184704.

doi:https://doi.org/10.1371/journal.pone.0184704

6. HOWLEY, T., 2016. Complete conditioning for Lacrosse. Champaign, Ill. [u.a.]: Human Kinetics.

7. IAICHE REZOUG, 2007. Evaluation De La Valeur Physique Des élèves Du Lycée Sportif National De Draria. Revue Scientifique Spécialisée des Sciences du Sport. 2(2), 40-45. Retrieved from https://www.asjp.cerist.dz/en/article/8472 
8. LÉGER, L. A., D. MERCIER, C. GADOURY \& J. LAMBERT, 1988. The multistage 20metre shuttle run test for aerobic fitness. J Sports Sci. 6(2), 93-101. doi:https://doi.org/10.1080/02640418808729800

9. Ling Qian, Lok-Wa Yuen, Yonghua Feng, Ian Newman, Duane Shell, Weijing, 2018. Effect of a Comprehensive Health Education Program to Increase Physical Activity among Primary School Students in China. Advances in Physical Education. 8(2), 196-204. doi:https://doi.org/10.4236/ape.2018.82018

10. MOHAMMED, Z., 2018. Physical Condition Test Standards: Best Missing Health Fitness Control Practises in Algerian Secondary School. Faculty of Sport and Physical Education of University of Montenegro, Montenegrin Sports Academy and FIEP.

11. MOHAMMED, Z., 2017. Impact of Prolonged Periods Classroom Settings in Intraabdominal fat area and its Consequence on Posture/Balance Control among Algerian Childhood College Preparatory School. International Journal of Applied Exercise Physiology. 6(2), 20-26. doi:https://doi.org/10.22631/ijaep.v6i2.88

12. ROBERT DAVIS, ROS PHILLIPS, JAN ROSCOE \& DENNIS ROSCOE, 2000. Physical Education and the study of sport. 4th ed. London: Harcourt Publishers.

13. WANG, Y., L. CAI, Y. WU, R. F. WILSON, C. WESTON, O. FAWOLE et al., 2015. What childhood obesity prevention programmes work? A systematic review and meta-analysis. Obes Rev. 16(7), 547-65. Retrieved from pmid:25893796

14. YANG, C., 2014. Effect on sports prescription education of 16 weeks for children obesity with 9-10 years old. Zhejiang Sport Science. 36(1), 101-28.

15. ZERF, M., 2016). Impact of theoretical courses on physical health performance. BLDE Univ $J$ Health Sci. 1, 44-48. Retrieved from http://www.bldeujournalhs.in/text.asp?2016/1/1/44/183285 